\title{
The influence of Media Violence on Aggressive Behaviour among Adolescents in Selected Secondary Schools in Ogbomoso, Nigeria.
}

\author{
Ojewola, F.O. PhD \\ Department of Guidance and Counselling, Adekunle Ajasin University, Akungba-Akoko Ondo-State, Nigeria
}

\begin{abstract}
The incidence of media violence on aggressive behaviour among adolescents has become a serious physiological, emotional and psychological issue. This study investigated the influence of media violence on aggressive behaviour among adolescents in secondary Schools in Ogbomoso. Descriptive survey research design was adopted for this study. The target population for the study was made up of all secondary school adolescents in Ogbomoso zone. Simple random sampling technique was used to select the six secondary schools from the forty public secondary schools, while two private schools were selected from the twelve viable ones. Total of 400 respondents were selected for the research work. Influence of Media Violence on Aggressive Behaviour Questionnaire (IMVABQ) was administered. The questionnaire contained twenty-five items with reliability co-efficient of 0.72. Three null hypotheses were generated and tested at 0.05 alpha level of significant. Descriptive, t-test, ANOVA and Duncan Multiple Range Test (DMRT) were the statistical tools used to analyze the data generated. The major findings indicated that there was no significant influence of media violence on aggressive behaviour on the basis of gender. The findings further showed that there was a significant influence of media violence on aggressive behaviour on the basis of age. While the result of the third hypothesis indicated that there was significant influence of media violence on aggressive behaviour on the basis of School type (private or public schools). Based on these findings, recommendations were made which include the need for professional counsellors to intensify effort in organizing counselling programmes for the adolescents on the evil of their exposure to violent media programme. Both parents and government should set up modalities to reduce the in flock of violent media programme in both private and national television stations. Again, there is the need for parents to be more vigilant in helping and censoring their adolescents 'consumption of violent media programmes.
\end{abstract}

Keywords: Media Violence, Aggression, Influence, Adolescents, and Gender.

\section{Introduction}

Media is entrenched in the lives of the generality of people that no day will pass without one accessing or interacting with one form of media or another. Media is not only for entertainment, but it used for information, education and enlightenment. Despite the numerous advantages that media has the depiction of violence has become a thing of serious concern to all and sundry. Media violence has become a contemporary and global issue which constitutes serious hardzard not only to the adolescents but to the entire populace. Over the years there has been growing concern over the effect of increase violence in the media (Paik \&Comstock, 1994; Anderson \&Bushman 2001; Huesmann; Eron\&Dubow,2003). There are different media medium, like the radio, television, videos, movies, video game, Computer network and so on. These are having tremendous impact on the lives, beliefs, values and general outlook of human beings.

Exposure to media violence could have far reaching effect not only on the children but also the adolescents, they are affected psychologically and physiologically. Adolescents that are prone to watching violent media programmes are often desensitized to violence thus they see it as a way of resolving conflict. According to Hogan (2005), continuous exposure to media violence can result in an increase acceptance of violence as an appropriate means of solving problems and achieving one's goal. While television movies and music videos normalize carrying and using of weapons, it also glamorizes them as sources of personal power (Federman, 1998). Media seems to have greater medium of shaping young people's attitudes and actions than do parents' or teachers' replacing them as educators, role models and primary sources of information about the world and how one behaves in it (Strasburger, 2006). Popular actors and actresses in current soap operas are often models and mentors for the adolescents. They tend to copy their hairdo, clothing styles, swaggers and even the way they speak and conduct themselves. Some even go to the extreme of copying their negative and contrary behaviour like sagging of the trousers and taking of hard drugs.

It has been observed that prolong exposure to media violence can have serious health implication such as anxiety, depression, sleep disturbances, nightmares, social isolation and post-traumatic stress. (Anderson, Berkowitz, Donnerstein, Huesmann, Johnson, Linz, Malamuth\&Wartella (2003) have associated exposure to media violence with a variety of physical and mental health problems for both children and adolescents. These problems includes aggressive, violent behaviour, bullying, desensitization to violence, fear depression, 
nightmares and sleep disturbance Huesmann, Moise-Titus,Pudolski and Eron (2003) also found that there is consistent and significant association between media exposure and increase in aggression and violence among Americans, and other cross cultural studies, field experiments, laboratory experiments, cross-sectional studies and longitudinal studies among children, adolescents and young adults.

There is an increase concern on the negative effect of media violence among adolescents. It is believe that exposure to violence on television and in video games may increase the risk of violent behavior on the viewers' part just like some that grow up in an environment filled with real violence increase the risk of violent behaviour. Huesmann, Eron and Dubow (2003) were of the opinion that a significant proportion of aggressive children are likely to grow to be aggressive adult. They also argued that seriously violent adolescents and adult were often highly aggressive and even violent as children. Huesmann at.al (2003) further noted that the best single predictor of violent behaviour in older adolescents, young adults and even middle aged adults is the occurrence of aggressive behaviour in childhood. Therefore, it is noted that exposure to media violence which could promote aggressive behaviour in young children may contribute to increasing aggressive and eventual violent behaviour many years later.

It has been observed that media violence affects both girls and boys. Some studies in United States and some other countries found stronger relations between media violence viewing and aggression for boys than for girls (Paik \& Comstock, 1994). Huesmenn, Eron\&Dubow (2003) found increasing rate of aggressions for both boys and girls who watched more television violence even when controlling for initial aggressiveness and many other background factors. It was also observed that $39 \%$ of females who are high violence viewers had "thrown something at their spouse in the past, while $17 \%$ of female had punched, beaten or choked another adult while angry in the past year. Furthermore, it could then be observed that there are some gender differences in the kinds of aggression associated with early childhood exposure t to media violence. According to Huesmann\&Taylor (2006) early exposure to violence predicted increase use of indirect aggression which includes telling lies to get colleagues in trouble more common among adult females than males. While early exposure to media violence had a stronger relation to physical aggression among adult males compared with females.

The incidence of media violence on aggression prompted this research effort. The adolescent mostly tend to enjoy these violent media programmes and some often watch them or play or interact with violent programmes as a way of catching fun, while away time or as hobbies. Quite often some of these adolescents do not consider media violence as a threat to their overall development. But whether it is accepted or not media violence is contributing adversely to many adolescents overall development and general outlook to life. It tends to create the culture of violence and threat in the nation. What with the various insurgent groups in Nigeria, the issue of Boko Haram, kidnapping and arm robbery has become very rampart with these youths. As a professional and trained counsellor urgent steps must be taken to solve or reduce the incidence of media violence among these youths to salvage the lives of these ones.

\section{Research Hypotheses}

1. There is no significant difference in the influence of media violence on aggressive behaviour on the basis of gender.

2. There is no significant difference in the influence of media violence on aggressive behaviour on the basis of age.

3. There is no significant difference in the influence of media violence on aggressive behaviour on the basis of School type.

\section{Research Design}

The research design adopted for this study was the descriptive survey method. The descriptive survey method involves the collection of data from a specific population in order to describe the present condition of the population using the variable under survey. Therefore, the researcher considered the method appropriate for the present study. This was used to investigate the influence of media violence on aggressive behaviour among adolescents in Ogbomoso, Nigeria.

\section{Sampling and Sampling Procedure}

The target population for the study are made up of all secondary school adolescents in Ogbomoso zone. There are 40 public secondary schools and twelve viable private Schools as of the time of conducting this research. Six secondary schools were randomly selected using simple random sampling technique. All secondary schools in Ogbomoso zone were written on pieces of paper and six secondary schools were randomly picked using the deep-hat procedure. Two private schools were also randomly selected from the existing list. This sampling technique was adopted because the manifestation of aggressive behaviour is high in these schools. This issue is peculiar to most adolescents in all these schools. Since the researcher could not involve all 
these adolescents, then there was the need for randomization for effectiveness and efficiency in all 400 respondents responded to the questionnaire.

\section{Research Design}

The instrument used for the collection of data in this study was developed by the researcher, titled. Influence of Media Violence on Aggressive Behaviour Questionnaire (IMVABQ). The items in the questionnaire were derived from the information obtained from the review of related literature. The instrument contains two sections. SECTION I deals with personal information about the respondents, while SECTION II has twenty-five items eliciting information on the influence of media violence on aggressive behaviour. The 4 point Likert-type response format was adopted for use in Section II.

$\begin{array}{lcc}\text { Very Much True of Me } & - & 4 \\ \text { True of Me } & - & 3 \\ \text { Rarely True of Me } & - & 2 \\ \text { Never True of Me } & - & 1\end{array}$

For each section, 4 was the highest score while 1 was the lowest score. The total score obtainable for a respondent with lowest score was 25 that is 1 × $25=25$. The highest possible score obtainable was 100 that is 4 x $25=100$. Therefore, the range was $100-25=75$. The midpoint was 37.5 , while the cut-off point was $100-$ 37.5 (i.e. maximum score minus the mid-point of the range) or $25+37.5$ (i.e. the minimum score plus $(+$ ) the midpoint of the range) in which either case was 62.5. Thus respondents who obtained scores from 62.5 to 100 were considered as those that were aggressive as a result of exposure to media violence. While those with score below 62.5 were considered not to be aggressive as a result of media violence. It had reliability co-efficient of 0.72

\section{Method of Data Analysis}

The data collected were analyzed using descriptive, t-test and ANOVA and Duncan Multiple Range Test (DMRT)statistical techniques to test the null hypotheses.

$\mathbf{H o}_{1}$ : There is no significant difference in the influence of media a violence on aggressive behaviour on the basis of gender.

Table 1: Means Standard Deviations, Degree of Freedom and t-values of the influence of media violence on aggression among male and female respondents.

\begin{tabular}{|l|c|c|c|c|c|c|}
\hline \multicolumn{1}{|c|}{ Gender } & No & \multicolumn{1}{c|}{ Mean } & SD & Df & Calculated t-value & Critical value \\
\hline Male & 201 & 61.46 & 8.92 & \multirow{2}{*}{398} & 0.00 & 1.96 \\
\hline Female & 199 & 61.46 & 9.17 & & & \\
\hline
\end{tabular}

Table 1: Shows that the calculated $t$-value 0.00 is lesser than the critical $t$-value of 1.96 at 0.05 alpha level of significant. Since the calculated $t$-value (0.00) is lesser than the critical $t$ value of (1.96), the null hypothesis was accepted. This means that there is no significant difference between male and female respondents on the influence of media violence on aggressive behaviour. There was different only in the standard deviation, but according to the mean it is the same score for the two groups but not significant as recorded in the t-test score.

$\mathbf{H O}_{2}$ : There is no significant difference in the influence of media violence on aggressive behaviour on the basis of age.

Table 2:Mean and Standard Deviation of respondents' on the basis of age on the influence of Media Violence on Aggressive Behaviour.

Total

\begin{tabular}{|c|c|c|c|}
\hline $\mathbf{N}$ & Age Range & Mean & Standard Deviation \\
\hline 80 & $9-12$ & 62.9 & 8.61 \\
\hline 230 & $13-16$ & 60.0 & 8.61 \\
\hline 90 & $17^{+}$ & 63.9 & 9.84 \\
\hline $\mathbf{4 0 0}$ & - & $\mathbf{6 1 . 4}$ & $\mathbf{9 . 0}$ \\
\hline
\end{tabular}

Table 2: shows the total number of respondents on the different age range. Age

Range 9-12, 80 respondents responded to the questionnaire with mean score of 62.9 and SD of 8.6, those in the second age range of 13-16 had the mean score of 60.0 and standard deviation of 8.6. While the last age range of $17^{+}$and above had the highest means score of 63.9 with the highest SD of 9.8. That is this set of people had the greatest influence of media violence than the other age groups. 
The influence of Media Violence on Aggressive Behaviour among Adolescents in Selected ....

Table 3: Analysis of Variance (ANOVA) Results on the Influence of Media Violence on Aggressive Behaviour on the Basis of Age.

\begin{tabular}{|c|c|c|c|c|c|}
\hline SOURCE & SUM OF SQUARES & DF & MEAN SQUARE & F CALCULATED & F CRITICAL \\
\hline $\begin{array}{c}\text { Between } \\
\text { Groups }\end{array}$ & 1201.782 & 2 & 600.891 & $7.60^{*}$ & 3.000 \\
\hline $\begin{array}{c}\text { Within } \\
\text { Groups }\end{array}$ & 31373.656 & 397 & 79.027 & \\
\hline TOTAL & $\mathbf{3 2 5 7 5 . 4 3 8}$ & $\mathbf{3 9 9}$ & & & \\
\hline
\end{tabular}

* Significant at 0.05 alpha level of significant $(\mathrm{p}<0.05)$

Tables 3: Shows that the calculated F-ratio of 7.60 is greater than the critical F-ratio of 3.00 at alpha level of significant. Since the calculated F-ratio of 7.60 is more than the critical F-ratio (3.00), the null hypothesis was rejected. This means that there is significant difference on the influence media of violence on aggression on the basis of age. Furthermore, since there is a significant difference among respondents on the influence of media violence using Analysis of Variance (ANOVA), the Duncan Multiple Range Test (DMRT) was used as a posthoc test to determine the age group(s) that was responsible for the significant difference noted in the ANOVA results in table 2

Table 4: Duncan Multiple Range Test (DMRT) showing Differences on the Influence of Media Violence among Adolescents on the Basis of Age

\begin{tabular}{|c|c|c|c|c|}
\hline $\begin{array}{c}\text { Duncan's } \\
\text { Grouping }\end{array}$ & Mean & No & Group & Age Range \\
\hline C & 60.0 & 230 & 1 & $13-16$ \\
\hline B & 62.9 & 080 & 2 & $9-12$ \\
\hline A & 63.9 & 90 & 3 & $17^{+}-$ \\
\hline
\end{tabular}

Note: Means having the same letters are not significantly different.

In table 3, the Duncan Multiply Range Test (DMRT) results was used to determine which of the age range mean that led to the significant differences noted in the ANOVA results table 2. The DMRT results showed that group 3 with a mean score of 63.9 is not far from Age range 2 with similar mean score of 62.9. It is quite different from group with a mean score of 60.0. Hence, the significant difference noted in the ANOVA results in table 2 was as a result of the fact that groups $3\left(17^{+}\right.$-Above years) and 2 (9-12) differed from group 1 (13-16). Thus, hypothesis 2 was rejected.

$\mathbf{H o}_{3}$ : There is no significant difference in the influence of media violence on aggressive behaviour on the basis of School type-Public/Private.

Table 5:Means, Standard Deviation, Degree of Freedom and t-values of the Influence of Media Violence on Aggressive Behaviour on the basis of School type.

\begin{tabular}{|l|l|l|l|l|c|c|}
\hline School Type & No & Mean & SD & DF & Cal t-value & Critical t-value \\
\hline Public & 298 & 63.0 & 8.9 & & & \\
\cline { 1 - 3 } Private & 102 & 57.0 & 7.8 & & & \\
\hline
\end{tabular}

Tables 5: Shows that the calculated F-ratio of 6.04 is greater than the critical F-ratio of 1.96 at 0.05 alpha level of significance. Since the calculated F-ratio (6.04) is greater than the critical F-ratio (1.96), the null hypothesis was rejected. This means that there is significant difference on the influence of media violence on aggressive behaviour between respondents in Public and those in the Private Schools.

\section{Discussion of Findings}

The results of the study showed that gender did not have influence on media violence on aggression among respondents used for the study. However, the results indicated significant difference on the basis of age range and school type.

Hypothesis one revealed that there was no significant difference on the influence of media violence on aggression on the basis of gender. Hence, both male and female respondents were equally affected by media violence.Huesmann and Laramie (2006) found that media violence affects both males and females: Huesmann, Eron and Dubow (2003) found similar effect sized for males and females older than 15years, however, they found that there was gender difference in the kinds of aggression associated with early childhood exposure to media violence. Again they found that early exposure to violence predicted increased use of direct aggression like telling lies to get colleagues in trouble among adult females but not males, while early exposure to media 
violence had a stronger relation to physical aggression among adult males compares with females. The bottom line is that exposure to media violence could influence both male and female adolescents.

The study also revealed that there was a significant difference on the influence of media violence on aggressive behaviour on the basis of age. There were three different age ranges $-9-12,13-16$, and $17^{+}$. The result indicated that those in the third age range level of $17^{+}$recorded greater influence than the other two age ranges. This lends credence to the findings of Paik and Comstock (1994) who found an inverse relationship between viewers' age and magnitude of the Television violence on aggression and other antisocial behaviour. Browne and Hamilton- Giachritsis (2005) observed that there is consistent evidence that violence imagery on television and in other media increases the likelihood of aggressive or fearful behaviour in younger children especially in boys. However, Kronenberger, Matthews, Dun, Yang, Wood, Larsen, Rembusch, Gianque and Lurito(2005) reported that children and adolescents exhibiting chronic, serve, aggressive behaviour are exposed to more television and video game violence than those not exhibiting such behaviour, even when controlling for intelligence, gender and age.

The third hypothesis found that there was a significant difference between respondents in public and private schools on the influence of media violence on aggressive behaviour. Those who are in the public school recorded greater mean of 63.00 than those in the Private schools with mean of 57.0. The students in the public schools seem to have more time to be engaged in video-games, watching of television programme and video tapes than those in private schools who are often bombarded with assignments and home work. This probably made it to be significant.

\section{Recommendations}

Professional counsellor should intensify efforts to organize intensive counselling programmes which can enlighten the governments, parents and even the students about the effect of media violence on the students and the impact on the society at large. Many students spend endless time watching violent TV programmes, playing videogames, viewing violent video clips, browsing violent internet programme. Many of these students have become cruel/wicked and could participate in any criminal activities without human feelings. Hence there is need to intensify effort to reduce these tendencies especially among the youths.

Professional and well trained counsellors should help adolescents to divert their skills and potentiality into more worthwhile ventures that will make their life more meaningful than engaging in violent media programmes.

Parents and government agencies especially those that are concerned with youths should rise to advocate for reduction of violent media programmes. Parents should monitor the time their adolescents spend on watching violent media and there is the need to censor the type of programmes they watch.

\section{References}

[1]. Anderson, C.A., Berkowitz, L., Donnerstein, L., Huesmann, L.R., Johnson, J.D., Linz. Malamuth, N.M. \&Wartella, E. (2003). Influence of Media violence on youth. Psychological Science in the Public Interest, 4 (3), 81 -110

[2]. Anderson, C.A. \& Bushman, B.J (2001). Effect of violence videogames on aggressive behaviour, aggressive cognition, aggress affect physiological arousal, and Prosocial behaviour: A meta analysis review of the Scientific Literature. Psychological Science,12 $: 353-359$.

[3]. Browne, K.D. \&Hanilton - Gachritsis, C. (2005). The influence of violent media on children and adolescents: A public - health approach. Lancet, 36: $702-710$.

[4]. Federman, J. (1998). National television violence study ed.Vol 3. Thousand Oaks:CA: Sage.

[5]. Hogan, M.J. (2005). Adolescents and media violence: Six crucial issues for practitioners. Adolescent Med. Clin. 16 (2) 249 - 268.

[6]. Huesmann, L.R., Eron, L.D. \&Dubow, E.F. (2003). Childhood predictors of adult criminality: Are all risk factors reflected in childhood aggressiveness? Crim. Behaviour Mental Health 12: 185 - 208.

[7]. Huesmann, L.R., Moise - Titus, J., Podolski, C.L \&Eron, L.D (2003). Longitudinal relations between children's exposure to TV violence and their aggressive and violent behaviour in young adulthood; (1977 - 1992) Dev. Psychol. 39: (2);201- 221.

[8]. Huesman, L.R \& Taylor, L.D. (2006).The role of media violence in violent behaviour. Journal of Public Health.27: $392-415$.

[9]. Kronenberger, W.G, Matthews, V.P., Dunn, D.W., Yang, W.I., Wood, E.A., Larsen, J.J., Rembusch, M.E., Lowe, M.J., Giauque, A.L.\&Lurito, J.T., (2005). Media violence exposure in aggressive and control adolescents: Differences in self and parentreported exposure to violence on television and videogames. Aggressive Behaviour. 31:201 -216.

[10]. Paik, H. \&Comstock, G. (1994). The effect of television violence on antisocial behaviour: A meta - analysis. Commun.Res.21: 516- 546 .

[11]. Strasburger, V.C. (2006). Risky business: What primary care practitioners need to know about the influence of the media on adolescents. Prim Care, 33 (2): 317348. 